\title{
Análisis del modelo de ingresos en medios nativos digitales de carácter alternativo de España
}

\author{
Analysis of the income model in alternative digital native media \\ of Spain
}

\author{
Tejedor, S. y Pla Pablos, A. 1 \\ Recibido: 08-11-2019 - Aceptado: 14-01-2020 \\ DOI: https://doi.org/10.26441/RC19.1-2020-A16
}

\begin{abstract}
RESUMEN: Los roles profesionales, la tipología de contenidos y las rutinas de producción de los medios de comunicación se han visto transformadas en el ciberespacio. La emergencia de medios nativos digitales con una idiosincrasia alternativa, más allá de los cibermedios generalistas ya consolidados, ha planteado además una serie de retos que afectan especialmente a la rentabilidad de estos proyectos periodísticos. Partiendo de ello, la investigación analiza diferentes modelos de ingresos de ocho cibermedios españoles alternativos a partir de un análisis comparativo de estudios de caso, entrevistas a sus fundadores y un grupo focal con usuarios. De este modo, la investigación concluye, entre otros aspectos, que en los cibermedios alternativos predomina una apuesta por modelos de ingresos centrados en la horizontalidad, la participación y el compromiso de los usuarios mediante contenidos que explotan la hipertematización mediante la diversidad y la especialización. El estudio advierte de la necesidad de diversificar las fuentes de financiación e identifica las suscripciones y el crowdfunding como las principales alternativas.
\end{abstract}

Palabras clave: periodismo; comunicación; negocio; ingresos; internet.

ABSTRACT: Professional roles, the type of content and the routines of production of the media have been transformed into cyberspace. The emergence of alternative digital native media, beyond the consolidated cybermedia created by and for the Network, has also raised a series of challenges that especially affect the profitability of these journalistic projects. Based on this, the research analyzes different income models of Spanish cybermedia based on a comparative analysis of eight case studies, interviews with its founders and a focus group with users. In this way, the research concludes, among other aspects, that a commitment to income models centred on horizontality, participation and user engagement is predominant through content that exploits the hypertematization through diversity and specialization. The study warns of the need to diversify funding sources and identifies subscriptions and crowdfunding as the main alternatives.

Keywords: journalism; communication; business; incomes; internet.

\footnotetext{
${ }^{1}$ Santiago Tejedor es Doctor en Periodismo por la Universidad Autónoma de Barcelona y Doctor en Ingeniería de Proyectos por la Universidad Politécnica de Cataluña. Es Director del Departamento de Periodismo y Ciencias de la Comunicación de la UAB y coordinador del grupo de investigación "Gabinete de Comunicación y Educación". santiago.tejedor@uab.cat, http://orcid.org/0000-0002-5539-9800
}

Ariadna Pla Pablos es Máster en Periodismo e Innovación en contenidos digitales por la Universidad Autónoma de Barcelona, Periodista e investigadora del ámbito de la comunicación y el periodismo. ariadna.plap@e-campus. uab.cat, https://orcid.org/0000-0002-6125-3947 


\section{Introducción}

En España existen más de 3.000 medios digitales (Salaverría et al., 2018). Entre el 30 y el 40\% de las nuevas empresas de medios creadas no logran sobrevivir al quinto año de haberse puesto en funcionamiento (Sembramedia, 2018) y, si lo hacen, deben implementar importantes ajustes (Rubio Hancock, 2019) que afectan a diferentes ámbitos de sus estructuras y dinámicas de funcionamiento. Esta tendencia, que define el panorama mediático español, es extensible a la estructura global de medios digitales. La irrupción de internet ha cambiado la manera en que se organizan los cibermedios y la forma de consumir la información, al tiempo que ha impulsado la aparición de nuevos proyectos y propuestas ciberperiodísticas. La red de redes ha generado un abaratamiento de los costes ligados a la ideación, creación y funcionamiento de un medio de comunicación. De este modo, han emergido nuevas revistas y medios digitales especializados en diferentes ámbitos temáticos. En este contexto, los cibermedios afrontan un proceso de transformación perenne (Neuberger, Nuernbergk, Langenohl, 2019) que afecta a sus sistemas de producción y distribución de contenidos, al perfil de las audiencias, a los roles periodísticos y, especialmente, a los modelos de negocio (García y González, 2012; Adira, Carmona et al, 2018). La necesidad de obtener rentabilidad y las transformaciones de la inversión publicitaria han obligado a los medios de comunicación digital a redefinir su estructura, tipología de contenidos y rutinas de producción periodística. En este sentido, autores como Pavlik (2005), Flores y Aguado (2005), Domínguez y Colomé (2012, 2013), Goyanes (2015), Jarvis (2015) o Chan-Olmsted y Shay (2016), entre otros, han advertido en sus trabajos sobre la necesidad de idear nuevos modelos de negocio para el escenario digital. En esta línea, Rodríguez y Soloaga (2017) o Palacio (2018) han incidido en la importancia de apostar por la generación de contenidos de calidad como la principal estrategia para obtener un retorno económico sólido en un escenario marcado por la infoxicación (Tejedor, 2007, 2017).

Partiendo de lo anterior, esta investigación analiza las características de los modelos de ingresos de diferentes cibermedios de carácter alternativo creados por emprendedores entre 2009 y 2019 en el escenario comunicativo español. La investigación lleva a cabo un estudio comparativo de ocho casos, un conjunto de entrevistas en profundidad a sus fundadores y un grupo focal con usuarios. De este modo, se comparan las especificidades de cada modelo de ingresos y se estudian sus principales particularidades. A partir de este objetivo general, la investigación ha respondido a los siguientes hitos específicos: 1) estudiar la tipología de contenidos y temas que ofrece cada uno de los cibermedios; 2) observar la tipología de formatos predominantes en su oferta informativa; y 3) analizar los elementos definitorios de sus respectivos modelos de ingresos. Con relación a estos interrogantes, el estudio se ha estructurado alrededor de las siguientes dos hipótesis de trabajo:

H1: Los medios nativos digitales alternativos han apostado por modelos de ingresos centrados en la horizontalidad, la participación y el compromiso de su público.

H2: Los medios nativos digitales alternativos respaldan su modelo de ingresos en una oferta temática que incide en contenidos centrados en la diversidad y en la especialización, potenciando una hipertematización que escasea en los cibermedios más consolidados.

\section{Marco referencial}

La crisis actual de los medios de comunicación no solamente está afectando a los medios tradicionales sino también a los medios nativos digitales. Éstos necesitan rentabilizarse y para ello deben buscar nuevas vías de ingresos en un escenario marcado por la caída de la inversión publicitaria y por un marcado protagonismo de la gratuidad. En este contexto, como apunta Palacio (2018), se plantea la necesidad de diversificar las vías de financiación, aunque no existe claridad sobre el modelo de ingresos más válido. A ello se une que la mayoría de investigaciones y trabajos académicos que han 
abordado la coyuntura española se han centrado en el estudio de los modelos de negocio (y, por ende, de ingresos) de medios de comunicación con cabeceras en papel y en digital o de medios nativos digitales consolidados (como eldiario.es o El confidencial, entre otros), dejando fuera del foco investigativo proyectos ciberperiodísticos con menor trayectoria y con una idiosincrasia alternativa.

El modelo de negocio alude a la forma en que una organización estructura un sistema de funcionamiento que busca alcanzar la sostenibilidad a partir de una serie de elementos clave para la consecución de ingresos y beneficios (Demil y Lecocq, 2009). Se trata, por tanto, de una planificación estratégica dirigida a potenciar, desde un planteamiento más holístico, la comprensión, la creatividad y reflexión sobre el proyecto desarrollado (Osterwalder y Pigneur, 2016). Destaca, en esta línea, el modelo Canvas que propone un esquema básico alrededor de la idea de negocio en cuatro áreas (clientes, oferta, infraestructuras y finanzas) y a partir de nueve elementos interrelacionados. Estos componentes siguen una secuencia lógica marcada por los siguientes indicadores: la propuesta de valor, las asociaciones estratégicas, las actividades clave, la relación con los clientes, el segmento de mercado, los recursos imprescindibles, los canales, la estructura de costos y las fuentes de ingresos (ver tabla 1).

Tabla 1. Áreas del modelo Canvas

\begin{tabular}{|l|}
\hline Clientes. 3 bloques: Segmentos de mercado, Canales y Relaciones. \\
\hline Oferta. 1 bloque: Propuesta de valor. \\
\hline Infraestructura. 3 bloques: Actividades clave, Recursos clave y Socios clave. \\
\hline Viabilidad económica. 2 bloques: Estructura de costes y Flujo de ingresos. \\
\hline
\end{tabular}

Fuente: Osterwalder (2010)

El modelo establece una serie de interrelaciones entre sus elementos (ver tabla 2). Por un lado, los apartados 1-5 aluden a elementos generadores de ingresos que sostienen el modelo de negocio; mientras que los apartados 6-9 indican la forma en que se realiza la oferta o propuesta de valor. La numeración contribuye además a establecer la secuencia de ejecución del esquema, siendo la propuesta de valor o los segmentos del mercado que queremos atender los puntos de inicio según la importancia que tengan uno u otro para el emprendedor. En este sentido, el modelo de negocio abarca a su vez el denominado modelo de ingresos, que constituye el objeto de estudio principal de la presente investigación.

Tabla 2. Elementos y secuencia del modelo Canvas

\begin{tabular}{|c|c|c|c|c|c|}
\hline \multirow[t]{2}{*}{\begin{tabular}{|l|} 
Socios \\
$\quad \mathbf{8}$ \\
Ayudan a \\
impulsar el \\
modelo de \\
negocio \\
\end{tabular}} & $\begin{array}{c}\text { Actividades } \\
\mathbf{7} \\
\text { Requeridas para } \\
\text { generar ingresos; en } \\
\text { las que se tiene buen } \\
\text { desempeño }\end{array}$ & \multirow{2}{*}{\multicolumn{2}{|c|}{$\begin{array}{c}\text { Propuesta de valor } \\
\mathbf{1 - 2} \\
\text { Única para cada segmento } \\
\text { (precio, novedad, calidad, } \\
\text { conveniencia, estatus, desempeño, } \\
\text { personalización) }\end{array}$}} & $\begin{array}{l}\text { Relación con los } \\
\text { clientes } \\
4\end{array}$ & \multirow[t]{2}{*}{$\begin{array}{l}\text { Segmentos del } \\
\text { mercado } \\
1-2 \\
\text { Clientes y } \\
\text { organizaciones } \\
\text { para las que se } \\
\text { crea valor }\end{array}$} \\
\hline & $\begin{array}{l}\text { Recursos } \\
\mathbf{6} \\
\text { Activos necesarios } \\
\text { para el negocio; } \\
\text { infraestructura para } \\
\text { crear, entregar y } \\
\text { conseguir valor }\end{array}$ & & & \begin{tabular}{|c|} 
Canales \\
$\mathbf{3}$ \\
Medio de contacto \\
con el cliente para \\
la entrega de la \\
propuesta de valor
\end{tabular} & \\
\hline \multicolumn{3}{|c|}{$\begin{array}{l}\text { Estructura de costos: con base en la infraestructura del } \\
\text { modelo de negocio } \\
\mathbf{9} \\
\text { Equilibrio con las fuentes de ingresos (no inicial) }\end{array}$} & \multicolumn{3}{|c|}{$\begin{array}{l}\text { Fuentes de ingresos } \\
\mathbf{5} \\
\text { os que generan valor para el modelo } \\
\text { de negocio }\end{array}$} \\
\hline
\end{tabular}

Fuente: Osterwalder (2010). 
Tradicionalmente, los cibermedios han basado su modelo de ingresos en alguna de estas tres tipologías: gratuidad, suscripción parcial y suscripción total (Flores y Aguado, 2005). Por un lado, el modelo gratuito se caracteriza por que los medios se financian mediante la publicidad y los recursos económicos de la editora matriz. Este tipo de modelo conlleva que todos los contenidos sean de acceso libre y que, por lo tanto, el medio deba buscar otras vías para financiarse como por ejemplo donaciones. Por su parte, el modelo mixto o de suscripción parcial, también llamado híbrido o freemium, presenta una parte de acceso libre junto a otras secciones o contenidos restringidos (como es el caso de The New York Times en EEUU o de Le Monde en Francia). En este caso, el usuario puede acceder a una serie de contenidos, pero no a su totalidad. Concretamente, en el modelo freemium, la mayoría de los servicios son gratuitos (freemium), pero existe un pequeño paquete de pago (premium) para los clientes que lo deseen. Junto a estas propuestas, que no han significado una desaparición de los ingresos por publicidad, ha irrumpido la financiación de iniciativas periodísticas, especialmente en sus fases embrionarias, mediante la lógica del crowdfunding que se apoya en la idiosincrasia colaborativa, horizontal y participativa de la web 2.0 o web social (Tejedor et al., 2018).

La cultura de la gratuidad de los contenidos ha constituido uno de los principales óbices en la detección de un modelo de ingresos eficaz. El informe Digital News Report de 2017, elaborado por el Instituto Reuters, apunta que la principal motivación de los usuarios para pagar por contenidos informativos se centra en aquellos servicios que les permiten acceso a través de sus teléfonos y tabletas. El estudio señala que existen internautas que pagan porque el contenido de pago es mejor que el gratuito, porque necesitan la información para su trabajo o porque quieren ayudar al periodismo contribuyendo económicamente. Según el mismo estudio, un 54\% de los usuarios no se suscribe a servicios informativos de pago porque consideran que puede obtener las noticias de forma gratuita; un $29 \%$ reconoce tener como principal fuente informativas páginas de acceso libre; un $25 \%$ considera que no vale la pena pagar por las noticias de internet; y un $22 \%$ afirma que prefiere consumir noticias off-line (Newman et al., 2017). El informe Digital News Report de 2018 señala que sólo un $44 \%$ de los internautas confía en los medios y un $34 \%$ en las noticias que encuentran en los buscadores de internet. El porcentaje de credibilidad en los contenidos difundidos por las redes sociales se reduce al 23\%. España se sitúa en la decimoctava posición del mundo respecto a la confianza que los ciudadanos poseen en los medios y, especialmente, en las noticias que éstos difunden (Newman et al., 2018). Según el último estudio Digital News Report (2019:13), se está produciendo una "fatiga de suscripción". El estudio advierte que los usuarios, especialmente los más jóvenes, prefieren pagar por contenidos de plataformas (como Netflix o Spotify) antes que pagar por contenidos informativos de cibermedios generalistas. En este contexto, la definición y aplicación de un modelo de ingresos eficaz constituye uno de los principales retos de la industria mediática. Este desafío está estrechamente unido a las particularidades de nuevo escenario comunicativo, así como al perfil y a los hábitos de los usuarios que lo definen.

La transformación digital ha impactado en el ámbito comunicativo generando una profunda modificación de los actores y de las estructuras tradicionales que participaban en el panorama mediático. Los agentes y los mercados de la información, la comunicación y la cultura adquieren nuevos roles e introducen nuevas dinámicas (Deuze, 2008). Este conjunto de cambios impacta en las particularidades de los modelos de ingresos y, al mismo tiempo, en los perfiles y comportamientos de los propios internautas. Tal y como apuntó Rheingold (2002), los nuevos usuarios reclaman un rol destacado en diferentes estadios del proceso comunicativo: participar, interactuar, dialogar y colaborar con los nuevos medios. El modelo de comunicación vertical y unidireccional ha sido desplazado por un escenario comunicativo donde predomina la horizontalidad, la interacción y la multidireccionalidad. En este escenario, los usuarios asumen una variedad de roles: productores y consumidores de contenido, emisores y receptores (Bruns, 2010, 2012). Casero-Ri- 
pollés (2012) concluye, en uno de sus trabajos, derivado de una encuesta a 549 usuarios, que la actualización, la multimedialidad, la personalización y los contenidos cotidianos y cercanos son las propiedades más valoradas por los internautas y, por ende, constituyen los pilares a partir de los cuáles edificar nuevos modelos de negocio en el ciberespacio. El trabajo de Carvajal y Valero (2018) estableció, tras una encuesta digital realizada a directores y editores de 37 compañías periodísticas españolas, que estos directivos preferían que sus modelos de negocio se respaldaran más en sus usuarios. Además, estos autores concluyen que los cibermedios que poseen dependen de la publicidad se plantean como uno de sus desafíos disminuirla hasta un nivel moderado en el futuro, pero sin prescindir de ella.

Autores como Kwak et al. (2010), Folker y Bruns (2017) o Nuernbergk (2016) inciden en sus trabajos sobre el proceso acelerado de transformación del sector periodístico, destacando que las organizaciones de noticias se han visto obligadas a adaptarse a los nuevos perfiles de usuarios y a las nuevas tipologías de contenidos. Chadwick (2013) advirtió que la supervivencia del periodismo estaba estrechamente vinculada a la capacidad de las redacciones para adaptarse a las transformaciones tecnológicas y a los nuevos hábitos de consumos, marcados por la irrupción de las plataformas colaborativas (Hedman y Djerf-Pierre, 2013; Primack, 2017). Desde la aparición de los primeros medios digitales, diferentes autores e investigadores han identificado una serie de retos que afectan de forma holística al conjunto del proceso comunicativo: el perfil de los periodistas, el cambio de hábito de los receptores, la tipología de contenidos, la modificación de las rutinas de producción, la irrupción de las redes sociales o el impacto del denominado big data (Haak, Parks y Castells, 2012). Entre los desafíos identificados, la definición y aplicación exitosa de un modelo de negocio rentable $\mathrm{y}$, por ende, de ingresos, para los cibermedios -especialmente, los nativos digitales- ha sido uno de lo más recurrentes.

En el escenario español, los trabajos pioneros de Edo (2002), Flores y Aguado (2005) López-García (2005) y Salaverría $(2005,2008)$ inauguraron una línea de investigación teórico-práctica sobre los modelos de negocios en el ciberespacio y los retos e interrogantes que éstos generaban. A ello se unieron las reflexiones de Diezhandino $(2008)$ y Cea Esteruelas $(2009,2013)$ sobre el modelo de negocio de las empresas periodísticas en el ciberespacio; Cabrera (2010), López y Pereira (2010) y Gago et al. (2013) sobre la reconfiguración de los medios en España a partir de la convergencia digital; y los trabajos de Vara (2011) y Vara y Díaz-Espina (2012) sobre la transformación de los ingresos publicitarios en internet. Posteriormente, las investigaciones de García-Avilés y González-Esteban (2012) centraron el foco en el modelo de negocio de los cibermedios nativos españoles. De este modo, y partiendo de este acervo teórico, como marco referencial y de antecedentes, la presente investigación se centra en el estudio de los modelos de ingresos de 8 cibermedios nativos españoles que han aparecido en la última década (2009-2019) y que responden al perfil de medios nativos digitales de carácter alternativo. Rosique y Barranquero-Carretero (2015) y Albalad (2018) aluden en sus respectivos estudios a la importancia de un periodismo lento que podría definirse como alternativo, caracterizado por presentar una organización, perseguir unos objetivos y potenciar una apuesta temática diferente y alejada de las grandes agencias de información y de los medios generalistas consolidados.

\section{Metodología e instrumentos}

La propuesta metodológica, de carácter documental y exploratorio (Vilches, 2011), ha aplicado tres técnicas de trabajo: el estudio de casos, la entrevista en profundidad y los grupos focales. Por un lado, el estudio de casos es un método de investigación cualitativo caracterizado por una primera fase de búsqueda e indagación sobre el tema en cuestión y una segunda fase de análisis (Yin, 1989). De este modo, se ha pretendido describir unos hechos o circunstancias a partir de una o varias hi- 
pótesis (que se mencionan en la introducción de este artículo) y la comparación o comprobación de estos fenómenos. Se trata, en definitiva, de una indagación estructurada alrededor de un ejemplo o buena práctica (Stake, 2005). En el marco de este trabajo, los estudios de casos permitieron examinar las plataformas nativas digitales existentes, hacer una selección (a modo de muestreo discrecional) y, finalmente, analizarlas desde dos perspectivas (por un lado, sus contenidos y, por otro, su propuesta de modelo de ingresos. Investigaciones como la Carvajal y Valero (2018) han contribuido a la diferenciación entre los conceptos de modelo de negocio y fuente de ingresos en el campo del periodismo.

La muestra de casos seleccionados fue concebida como el conjunto de elementos de la población a los que se pide que participen en la investigación (Del Rincón, Arnal, Latorre y Sans, 1995). La investigación ha apostado por muestreo discrecional o más comúnmente conocido como muestreo intencional. En este tipo de toma de muestras, los sujetos sometidos a análisis y estudio son elegidos por el investigador para formar parte de la muestra con un objetivo específico (Vilches, 2011). El diseño de la investigación identifica un conjunto de sujetos como más adecuados para la investigación. Partiendo de ello, la muestra ha tenido en consideración los siguientes indicadores: 1) referencias de expertos del sector; 2) naturaleza nativa digital; 3) apuesta por nichos de mercado muy específicos; 4) contenidos de carácter especializado; y 5) voluntad de ofrecer una alternativa informativa frente a los medios generalistas. En total se han analizado los siguientes ocho cibermedios del ecosistema mediático español: Ctxt, 5W, Jot Down, FronteraD, Gadwoman, Modaes, Hemisferia.cat y Crític.

La selección de este conjunto de proyectos ciberperiodísticos se ha realizado teniendo en cuenta una consulta a expertos, su naturaleza de medios nativos digitales, su apuesta por nichos de mercado tematizados y su voluntad de ofrecer unos contenidos alternativos (tal y como apuntan en sus respectivos sitios web al presentar su proyecto) frente a los cibermedios consolidados del panorama mediático español. En todos los casos se trata además de medios nativos digitales creados en la última década (entre 2009 y 2019). En cada caso, el análisis se realizó, en una primera fase, a través de una ficha (ver tabla 3 ) que abarcó tanto aspectos de la tipología del cibermedio como sus características temáticas y, especialmente, las particularidades de su modelo de ingresos.

Tabla 3. Análisis de los cibermedios

\begin{tabular}{|l|l|}
\hline Identidad del cibermedio & \multicolumn{1}{|c|}{ Modelo de ingresos } \\
\hline Año de creación & Tipo de sociedad \\
\hline Fundadores & Tipo de modelo de ingreso \\
\hline Director & Fuentes de financiación \\
\hline Temática & \\
\hline Secciones & \\
\hline Tipo de contenido & \\
\hline Formato & \\
\hline Propuesta de valor & \\
\hline
\end{tabular}

Fuente: Elaboración propia (2019).

En una segunda etapa del estudio se procedió a entrevistar a los fundadores o principales responsables de cada uno de los cibermedios seleccionados (ver tabla 4). Las entrevistas en profundidad, concebidas como una técnica estructurada de encuentros entre el investigador y los informantes (Rodríguez, Gil \& García, 1996), buscaron la comprensión de las perspectivas que estos poseen respecto a diversas temáticas, experiencias o situaciones (Taylor y Bodgan, 1994; Rincón, 1995). Las entrevistas, de carácter inédito, han permitido acceder y comparar los testimonios de los impulsores de los ocho proyectos de cibermedios nativos digitales seleccionados. 
Tabla 4. Listado de periodistas entrevistados

\begin{tabular}{|l|l|l|}
\hline Nombre del entrevistado & Cargo & Nombre del medio \\
\hline Miguel Mora & Fundador & Ctxt \\
\hline Maribel Izcue & Redactora jefe & $5 W$ \\
\hline Christian de Angelis & Fundador & Modaes \\
\hline Carmen Jané & Fundadora & Gadwoman \\
\hline Martí Puig & Fundador & Hemisfèria.cat \\
\hline Ángel Fernández & Fundador & Jot Down \\
\hline Sergi Picazo & Fundador & Crític \\
\hline Alfonso Armada & Fundador & FronteraD \\
\hline
\end{tabular}

Fuente: Elaboración propia (2019).

Las entrevistas, de cariz semiestructurado, se han diseñado a partir de un formulario de preguntas abiertas, ideadas mayoritariamente para fomentar la reflexión de índole cualitativa. El cuestionario de las entrevistas fue validado por un panel de expertos $(n=10)$ en materia de periodismo. Los participantes fueron informados del estudio y su consentimiento fue solicitado para participar en el mismo. El proceso de realización y procesamiento de las entrevistas se llevó a cabo entre los meses de enero a junio de 2019. Las principales variables temáticas de los guiones de las entrevistas fueron las siguientes: a) rasgos definitorios del modelo de negocio aplicado; b) justificación de la elección; c) principales fuentes de ingreso; d) principales retos y dificultades; e) perspectiva de futuros y análisis de posibles tendencias en el sector; f) cibermedios de referencia a nivel mundial.

Finalmente, se desarrollaron dos grupos focales con 15 alumnos de comunicación de tercer ciclo que, en todos los casos, acumulaban experiencia en el ámbito ciberperiodístico. El grupo focal, concebido como una técnica cualitativa que estudia las opiniones o actitudes de un público, ha sido de gran utilidad para el análisis de la concepción, la valoración y las reflexiones de estos usuarios respecto a los cibermedios seleccionados (Samperi, Collado y Lucio, 2010). El objetivo era provocar autoexposiciones entre los participantes en aras de obtener información cualitativa sobre el tema de investigación (Jurgenson, 2003). Para esta investigación se realizaron dos grupos focales, de entre 90 y 120 minutos de duración, destinados a averiguar posibles fórmulas, tendencias de éxito y estrategias relacionadas con la ideación de un modelo de ingresos solvente para cibermedios nativos digitales no generalistas.

Cada uno de los grupos estuvo integrado por estudiantes de comunicación, tanto hombres como mujeres, de edades comprendidas entre los 22 y los 30 años. La elección de estudiantes de comunicación respondió a la voluntad de poder establecer escenarios propositivos de discusión y reflexión con usuarios duchos en el acervo terminológico del ámbito analizado y, por ende, con mayor capacidad para la formulación de propuestas sobre el asunto tratado. Resulta importante clarificar este aspecto, ya que responde a la voluntad, a nivel metodológico, de generar autoexposiciones a partir de perfiles con experiencia en el tema (Jurgenson, 2003). Las preguntas y temáticas abordadas durante los encuentros fueron los siguientes: a) Gratuidad o pago; b) Tipología de contenidos por los que pagarían; c) Elementos que valora como usuario de cibermedios; d) Fortalezas y debilidades de los ocho proyectos seleccionados en el marco del estudio; e) Hábitos de consumos de cibermedios; f) Medios referentes a nivel de modelo de negocio; g) Opinión sobre la publicidad digital; h) Valoraciones y perspectivas de futuro; y i) Propuestas para la redefinición de los modelos de ingresos.

\section{Análisis de los resultados}

A partir de la metodología expuesta, a continuación, se describen los resultados de mayor importancia en una secuencia lógica que analiza cada uno de los cibermedios que integran la muestra, al tiempo que aporta un análisis detallado de sus características más allá de la ficha de análisis definida y aplicada en el marco de la investigación. 
Ctxt (https://ctxt.es/), el primer cibermedio analizado, consiste en una revista que nace en 2015, cuando catorce periodistas procedentes de grandes diarios europeos advirtieron la necesidad de crear un medio que apostará por el análisis periodístico más allá de los contenidos marcados por los servicios de la última hora (ver tabla 5). Ctxt pertenece a Revista Contexto S.L., su empresa editora. Se trata de una revista digital que, bajo el lema "orgullosos de llegar tarde a las últimas noticias", proporciona noticias contextualizadas sobre política, economía, temas de alcance internacional y comunicación. Asimismo, también cuenta con una sección llamada "especiales" donde el usuario puede encontrar entrevistas, reportajes, perfiles y otras piezas de distintas temáticas. Su propuesta de valor consiste en aportar contexto político y económico a las noticias más relevantes, promover el debate y analizar los hechos con sentido crítico y honestidad. Su formato es equilibrado y analítico, con un texto largo, bien escrito y con información cuidadosamente verificada. Aparte de la revista digital, Ctxt comercializa también un semanario en papel llamado El Dobladillo.

Tabla 5. Ficha de análisis de Ctxt.

\begin{tabular}{|l|l|}
\hline \multicolumn{2}{|l|}{ Identidad del cibermedio } \\
\hline Año de creación & 2015 \\
\hline Fundadores & 14 periodistas \\
\hline Director & Miguel Mora \\
\hline Formato & Revista digital y semanario \\
\hline Temática & Noticias de contexto \\
\hline Secciones & $\begin{array}{l}\text { Política (Internacional, España, Economía, Comunicación) } \\
\text { Firmas (Columnas, Editoriales, llustraciones, Tribunas y Debates) } \\
\text { Culturas (Artes y Letras, Ciencia y Tecnología, Viajes y Ficciones) } \\
\text { Multimedia } \\
\text { Deportes }\end{array}$ \\
\hline Tipo de contenido & Generalista y especializado \\
\hline Propuesta de valor & $\begin{array}{l}\text { Aportar contexto político y económico a las noticias más relevantes, } \\
\text { promover el debate y analizar los hechos con sentido crítico }\end{array}$ \\
\hline Modelo de ingresos & Sociedad Limitada \\
\hline Tipo de sociedad & Híbrido: Contenido gratuito y suscripción \\
\hline Tipo de modelo de negocio & Suscripciones, donaciones, publicidad, editorial, tienda, cursos y talleres \\
\hline Fuentes de ingresos & \\
\hline
\end{tabular}

Fuente: Elaboración propia (2019)

La revista está presente en redes sociales como Twitter, Facebook, Instagram, Youtube y Telegram, donde acumulan miles de seguidores y presentan una actividad intensa. El contenido de Ctxt es totalmente gratuito y abierto a los usuarios bajo la creencia de que el periodismo tiene que ser un servicio público. Sin embargo, el medio ofrece la opción de suscribirse y obtener algunas ventajas mediante cuatro tipos de suscripciones diferentes con descuentos para estudiantes, parados y jubilados (ver gráfico 1). El precio oscila entre los 2,5 euros y los 6,25 euros al mes dependiendo de la opción elegida. Además, todas las suscripciones incluyen acceso a "El Saloncito", que es la zona de suscriptores del medio, la carta semanal y adelantos editoriales. En 2017, Ctxt llegó a 5.000 suscriptores, que aportaban el $53 \%$ de los ingresos totales. 
Gráfico 1. Modalidades de suscripción

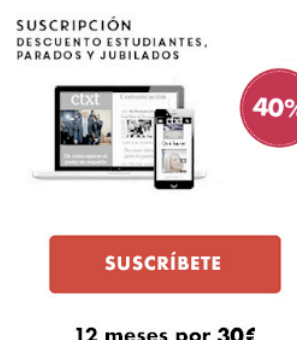

12 meses por $30 €$

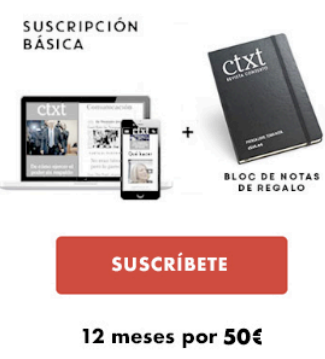

12 meses por $50 €$

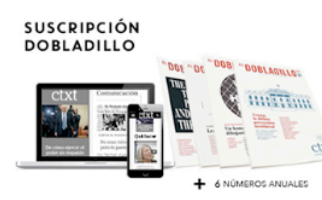

SUSCRíBETE

12 meses por $60 €$

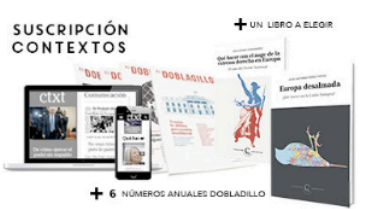

\section{SUSCRÍBETE}

12 meses por $75 €$

Fuente: https://agora.Ctxt.es

Ctxt nació a partir de las indemnizaciones de los 14 periodistas y una campaña de crowdfunding que les permitió sacar el proyecto adelante. Para sus fundadores, la mayor dificultad ha sido construir un modelo de ingresos alternativo a la publicidad. Los dos primeros años desde su creación tuvieron pérdidas y el trabajo de los integrantes no fue remunerado. No obstante, a partir del segundo año empezaron a generar beneficios situándose en 2017 con 2.363 euros en positivo y con 23.214 euros en 2018. A finales del segundo año ya pudieron establecer los sueldos y, desde entonces, su modelo de ingresos se ha basado principalmente en las suscripciones, que producen un $40 \%$ de los ingresos totales. Otro $10 \%$ proviene de la publicidad y el resto se concentra en las ventas que hacen a través de una pequeña editorial llamada "Ctxt-Lengua de trapo", que publica libros de autores que firman en Ctxt; las donaciones, los patrocinios y la organización de eventos (como las jornadas de feminismo que realizan cada año), los cursos y talleres de periodismo que imparten y una tienda online.

El estudio de caso del cibermedio $5 W$ (www.revista5w.com) permite identificar el proyecto como una revista digital de crónica de larga distancia que confiere un gran protagonismo al componente fotográfico. Fue fundada en 2015 por un grupo de nueve periodistas procedentes de distintos medios de comunicación que apostaron por un periodismo de contexto. Su nombre se inspira en las conocidas como cinco "W" (Who, What, When, Where, Why) del periodismo. El proyecto defiende que los sucesos internacionales no pueden contarse con tan sólo 140 caracteres ni tampoco en una página, sino que requieren una explicación mucho más extensa. Además de la revista digital, el proyecto edita una revista anual en papel y emite un programa de radio mensual (ver tabla 6).

Tabla 6. Ficha de análisis de $5 \mathrm{~W}$

\begin{tabular}{|c|c|}
\hline \multicolumn{2}{|r|}{ Identidad del cibermedio } \\
\hline Año de creación & 2015 \\
\hline Fundadores & 9 periodistas \\
\hline Director & Agus Morales \\
\hline Formato & Revista digital, revista anual (papel) y programa de radio mensual \\
\hline Temática & Crónica y fotografía internacional \\
\hline Secciones & $\begin{array}{l}\text { Crónicas } \\
\text { Por zonas } \\
\text { Especiales } \\
\text { Podcast }\end{array}$ \\
\hline Tipo de contenido & Especializado y crónicas en profundidad \\
\hline Propuesta de valor & Apuesta por la narración, profundidad, explicación, la imagen y el sonido \\
\hline \multicolumn{2}{|r|}{ Modelo de ingresos } \\
\hline Tipo de sociedad & Sociedad Limitada \\
\hline Tipo de modelo de negocio & Híbrido: gratuito y suscripción \\
\hline Fuentes de ingresos & Suscriptores, revista en papel, libro Voces $5 \mathrm{~W}$, publicidad, eventos y talleres \\
\hline
\end{tabular}

Fuente: Elaboración propia (2019). 
El proyecto $5 \mathrm{~W}$ es una sociedad limitada sin un accionista mayoritario. Todos los fundadores tienen la misma participación en la empresa. La iniciativa cuenta con decenas de colaboradores distribuidos por el mundo. Se trata de una revista digital que, bajo uno de sus lemas "pequeñas historias, grandes explicaciones", se preocupa por contar los sucesos internacionales y las historias concretas de manera contextualizada y detallada. Se divide en cuatro secciones que reciben el nombre de: "Crónicas", "Por zonas", "Especiales" y "Podcast". La primera sección contiene entrevistas, perfiles, reportajes, vídeos y ensayos fotográficos. La segunda se subdivide en cinco pestañas que corresponden a los continentes donde el usuario puede encontrar crónicas de cada uno de ellos. La tercera presenta reportajes inéditos y, por último, se encuentra el apartado de podcast que graban mensualmente los propios redactores del medio.

Gráfico 2. Página de inicio del cibermedio $5 W$.

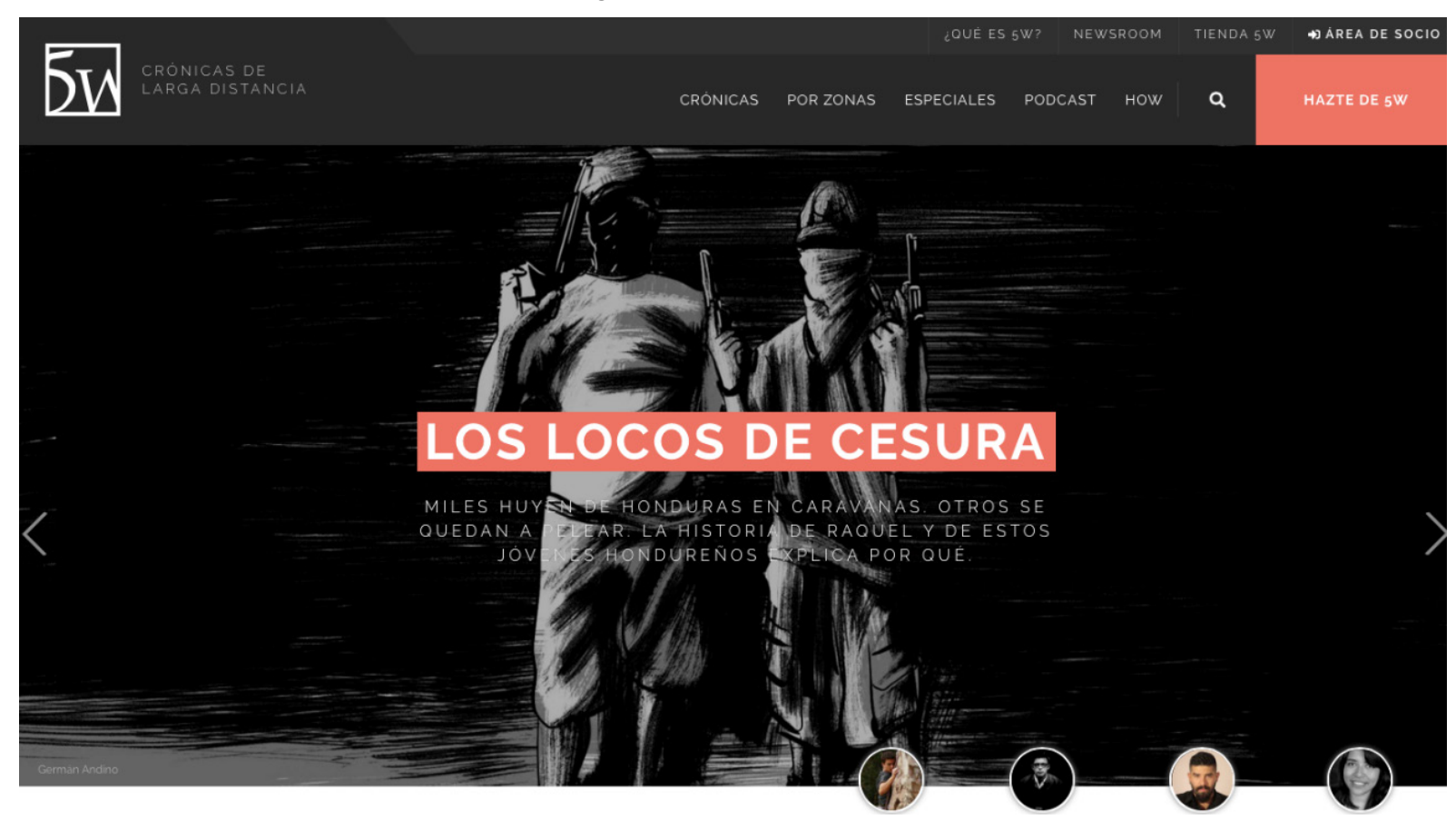

Fuente: www.revista5w.com

Su propuesta de valor, junto a la crónica internacional, se centra en contar historias de los lugares más remotos del planeta y de las personas que viven en ellos. El cibermedio parte del supuesto de que existen muchas historias lejos de nosotros que desconocemos y que merecen ser contadas, $\mathrm{y}$ que éstas no admiten un simple sí o un no, sino respuestas mucho más complejas que respondan a muchas preguntas que surgen después de leer una noticia o verla en televisión. Por ese motivo, el formato de los textos es extenso. Además, publican una revista anual en papel de tapa dura y hacen un programa de radio mensual. El contenido de $5 W$ es gratuito, a pesar de que las crónicas semanales permanecen cerradas cuando se publican y durante algunas semanas. Sólo pueden acceder a ellas los suscriptores (hasta que, posteriormente, las abren al público). De esta forma, los socios pueden ver la información en primicia, pero ésta acaba llegando a todo el mundo. El medio ofrece dos tipos de suscripciones que oscilan entre los 3 euros y los 5 euros. El usuario también tiene la opción de elegir su cuota personalizada y pagar lo que crea conveniente (aunque en todos los casos tiene ventajas, descuentos, recibe newsletters y en algunos casos también el libro Voces $5 \mathrm{~W}$, que se publica anualmente, y la revista anual en papel de tapa dura). En la actualidad, el proyecto posee alrededor de 2.900 suscriptores. 
Gráfico 3. Modalidades de suscripción al cibermedio $5 \mathrm{~W}$

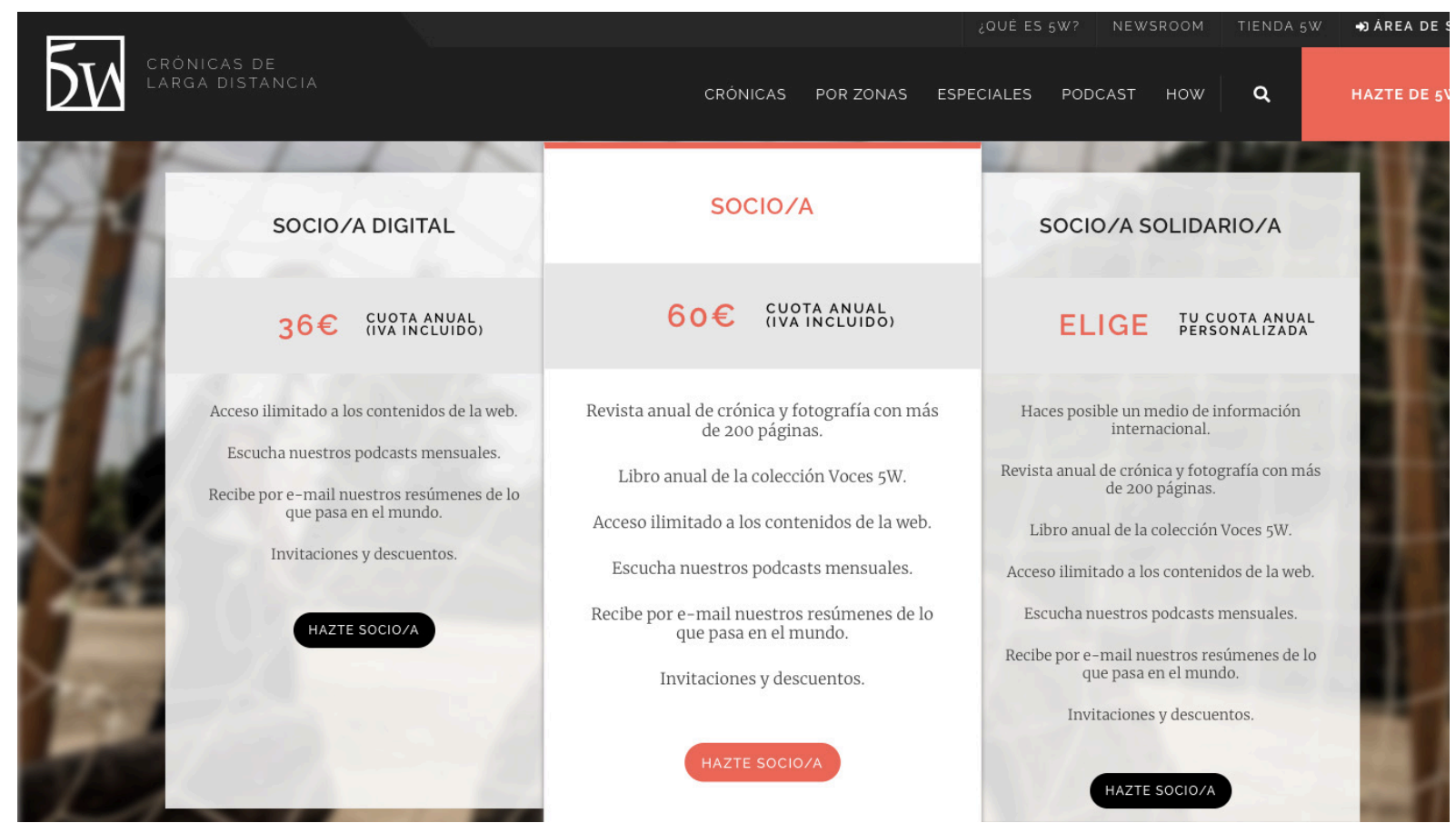

Fuente: www.revista5W.com/suscripciones-socios

El lanzamiento del proyecto se realizó en 2015 a través de las redes sociales y mediante una campaña de micromecenazgo a través de Verkami (www.verkami.com). Un año después, sacaron su primer número en papel. Su modelo de ingresos se basa mayormente en las suscripciones, pues un $70 \%$ de los ingresos totales proviene de las mismas. La venta de sus dos productos en papel representa otra fuente de financiación, junto con un $2 \%$ de publicidad y algunos talleres, exposiciones y otro tipo de eventos.

Tabla 7. Ficha de análisis de Modaes

\begin{tabular}{|c|c|}
\hline \multicolumn{2}{|r|}{ Identidad del cibermedio } \\
\hline Año de creación & 2009 \\
\hline Fundadores & Pilar Riaño y Christian De Angelis \\
\hline Director & Pilar Riaño y Christian De Angelis \\
\hline Formato & Diario económico online \\
\hline Temática & Medio económico especializado en el sector de la moda \\
\hline Secciones & $\begin{array}{l}\text { Empresa (Noticias sobre empresas y marcas) } \\
\text { Entorno (Datos estadísticos en países) } \\
\text { Tendencias (Eventos, ferias, pasarelas, etc.) } \\
\text { Back Stage (Entrevistas, mapeos, etc.) } \\
\text { Equipamiento } \\
\text { Cosmética (cosmética, perfumería, etc.) } \\
\text { Look! (marcas, pasarelas, etc.) }\end{array}$ \\
\hline Tipo de contenido & Noticias y artículos sobre moda y economía \\
\hline Propuesta de valor & $\begin{array}{l}\text { Plataforma de servicios multicanal que da respuesta a } \\
\text { profesionales del sector partiendo de la información }\end{array}$ \\
\hline \multicolumn{2}{|r|}{ Modelo de ingresos } \\
\hline Tipo de sociedad & Sociedad Limitada \\
\hline Tipo de modelo de negocio & $\begin{array}{l}\text { Freemium. Hay parte del contenido gratuito. Posibilidad } \\
\text { de hacerse premium y obtener más ventajas }\end{array}$ \\
\hline Fuentes de ingresos & Publicidad, suscripciones, revista en papel \\
\hline
\end{tabular}

Fuente: Elaboración propia (2019). 
El cibermedio Modaes (www.Modaes.es) es un diario digital especializado en noticias económicas sobre la moda que nació en 2009 (ver tabla 7). La iniciativa surgió en el momento en que sus dos fundadores detectaron el nicho sin cubrir y las posibilidades que ofrecía crear un portal de noticias alrededor de la moda, pues los medios tradicionales no prestaban suficiente atención a la información económica de este sector de gran peso en la economía española.

La empresa es una sociedad limitada que actualmente cuenta con una plantilla de treinta trabajadores. Se trata de un medio digital especializado que se divide en siete secciones ("Empresa", "Entorno", "Tendencias", "Back Stage", "Equipamiento", "Cosmética” y "Look!"). A través de diferentes formatos y herramientas interactivas como gráficos o mapas enriquecidos, entre otros, complementan sus entrevistas e información sobre el negocio de la moda, que suele ser en formato noticia. Sin embargo, su propuesta de valor no es sólo proporcionar información económica sobre el sector, sino también ser una plataforma de servicios multicanal que da respuesta a profesionales del sector partiendo del componente informativo. Su especialización le permite posicionarse a nivel español y dirigirse a un sector de la audiencia muy determinada. Actualmente, Modaes se encuentra en una fase de internacionalización, ya que desde hace unos años cuenta con una edición online en Latinoamérica que han conseguido posicionarse ampliamente en la región. También están en una fase de pre lanzamiento de una edición online en inglés. Además del sitio web, publican una revista trimestral en papel gratuita para los suscriptores. Su principal reto ha sido la búsqueda de la rentabilidad económica. El medio nació como una empresa pequeña sin capacidad para tener publicidad ni llegar a una gran audiencia. Otro de los retos fue conseguir clientes y convencerles de que apostaran por el medio. En cuanto al modelo de ingresos, el 95\% de su contenido en la web es abierto mientras que el $5 \%$ restante es sólo para suscriptores premium. El precio por suscripción es de 100 euros anuales, es decir, unos 8,3 euros al mes. No obstante, las suscripciones solamente representan entre un 7 y un $8 \%$ de los ingresos totales junto con las ventas de la revista en papel. El resto de los ingresos proviene de la publicidad, que es su mayor fuente de financiación y cuyo protagonismo es muy importante en el sitio web del cibermedio.

Tabla 8. Ficha de análisis de Gadwoman

\begin{tabular}{|l|l|}
\hline Año de creación & \multicolumn{1}{c|}{ Identidad del cibermedio } \\
\hline Fundadoras & Toñi Herrero y Carmen Jané \\
\hline Director & Toñi Herrero y Carmen Jané \\
\hline Formato & Revista digital femenina de tecnología \\
\hline Temática & Mujer y tecnología \\
\hline Secciones & $\begin{array}{l}\text { Contigo (móviles y tabletas) } \\
\text { Internet (redes sociales, apps, etc.) } \\
\text { Trabajo (emprendimiento, mejora profesional, productividad, autoayuda, etc.) } \\
\text { Casa (la tecnología que puedes tener en casa: televisión, equipo de música, } \\
\text { robots de cocina, etc.) } \\
\text { Familia (apps y gadgets para niños, maternidad, etc.) } \\
\text { Ocio (apps de películas, fotografía, música, vídeo, juegos, etc.) }\end{array}$ \\
\hline Tipo de contenido & Tutoriales e información útil a la que se pueda recurrir \\
\hline Propuesta de valor & $\begin{array}{l}\text { Romper con el estereotipo de que la tecnología es algo masculino y dar visibilidad } \\
\text { a las mujeres frente a esta tecnología, es decir proporcionar información sobre } \\
\text { tecnología desde una perspectiva de género }\end{array}$ \\
\hline Tipo de sociedad & Sociedad Limitada \\
\hline Tipo de modelo de negocio & Contenido gratuito \\
\hline Fuentes de ingresos & Aportaciones propias, publicidad \\
\hline
\end{tabular}

Fuente: Elaboración propia (2019). 
El cibermedio Gadwoman (https://Gadwoman.com) es una revista digital de información sobre tecnología desde una perspectiva de género. El proyecto nace en 2011 cuando sus dos fundadoras consideran que las páginas tecnológicas no explicaban para qué servían las cosas. Por otra parte, quisieron romper con el estereotipo de que las mujeres no están interesadas en los aspectos tecnológicos y que la tecnología es algo masculino (ver tabla 8).

Se trata de una revista digital donde solamente trabajan las dos fundadoras junto a la ayuda de colaboradores puntuales. Gadwoman se divide en seis secciones ("Contigo", "Internet", "Trabajo", "Casa", "Familia" y "Ocio") que a su vez se subdividen en otros apartados. El formato de sus textos es de extensión variable, de cariz informativo y con información práctica que suele presentarse como recomendaciones o consejos. El cibermedio aborda temas como el emprendimiento y la mejora profesional, nuevos aparatos electrónicos para niños y aplicaciones de fotografía, vídeo o música, entre otros. Su propuesta de valor es empoderar a las mujeres y ofrecer información útil al usuario mediante directrices, manuales o tutoriales. Su contenido es totalmente gratuito. En este sentido, la publicidad es su principal fuente de ingresos junto con el capital propio. Su mayor reto ha sido definir el modelo de ingresos y compaginar sus trabajos con Gadwoman, además de la creación de la empresa, pues ninguna de las fundadoras poseía conocimientos del mundo empresarial ni de los aspectos más técnicos como el funcionamiento y creación del sitio web. Otra de las dificultades ha sido la difusión, ya que el trabajo en redes sociales ha resultado complicado.

El proyecto de cibermedio Hemisfèria (https://hemisferia.cat) es un medio de comunicación digital de crónica internacional escrito en lengua catalana. Nació en 2015 como un proyecto de diez estudiantes universitarios sin ninguna perspectiva de negocio y con el tiempo se convirtió en su negocio profesional. Su objetivo es dar cobertura a todos aquellos temas y países que son a menudo olvidados por los grandes medios y hacerlo desde el lugar de los hechos y en formato crónica (ver tabla 9).

Tabla 9. Ficha de análisis de Hemisfèria

\begin{tabular}{|l|l|}
\hline Año de creación & Identidad del cibermedio \\
\hline Fundadores & 10 estudiantes universitarios \\
\hline Formato & Revista digital + revista papel \\
\hline Temática & Crónica internacional \\
\hline Secciones & $\begin{array}{l}\text { Secciones (Derechos humanos, Migración, Religión, } \\
\text { Racismo, Género, Economía, y Cultura) } \\
\text { Mundo } \\
\text { Reportajes } \\
\text { Crónicas } \\
\text { Análisis } \\
\text { Entrevistas } \\
\text { La tercera voz }\end{array}$ \\
\hline Tipo de contenido & Especializado en formato crónica \\
\hline Propuesta de valor & Crónica internacional de proximidad \\
\hline Tipo de sociedad & Asamblea de ingresos \\
\hline Tipo de modelo de negocio & Contenido gratuito \\
\hline Fuentes de ingresos & Crowdfunding, publicidad, revista papel y donaciones \\
\hline
\end{tabular}

Fuente: Elaboración propia (2019).

Hemisfèria se estructura en forma de asamblea, por lo que todas las decisiones se discuten y se toman en consenso. No hay un único director, sino que los mismos fundadores ejercen esa función. Actualmente, solamente seis de los diez fundadores siguen dirigiendo el medio, aunque cuentan con colaboradores en todos los continentes. La revista se estructura en doce secciones ("Conflicto", 
"Planeta”, "Instituciones", “Cultura", "Historia", "Economía”, “Derechos humanos", "Migración”, "Religión", "Género", "Vivienda" y "Racismo"). Asimismo, también hay otros apartados con entrevistas, perfiles y reportajes. El formato predominante es la crónica. El contenido es totalmente gratuito y publican también una revista en papel. La iniciativa se impulsó a partir de una primera campaña de crowdfunding a través de Verkami. Más adelante hicieron dos más. Una de ellas fue con la Fundación Goteo, a la que solicitaron financiamiento para realizar un proyecto específico con el Ayuntamiento de Barcelona y por el que consiguieron unos 8.000 euros, cifra que les permitió seguir manteniendo la plataforma, pagar a sus trabajadores y cubrir los costes del proyecto. Otra fuente de ingresos es la venta de su revista en papel por un precio de 3,5 euros. La publicidad a través de Google AdSense es otra de sus fuentes de financiación, aunque supone una parte muy pequeña del total. Por último, ofrecen la posibilidad al usuario de hacer donaciones en su sitio web.

El cibermedio Crític (www.elcritic.cat) es un medio de comunicación digital especializado en periodismo de investigación (ver tabla 10). Nació en 2014 con la voluntad de reivindicar el slow journalism y huir del "fast food informativo" y del "periodismo de tuits". El proyecto fue impulsado por la cooperativa de periodistas Crític SCCL, pero cuenta además con sesenta socios colaboradores que también han contribuido económicamente en el proyecto. Se trata de un medio digital independiente sobre actualidad política, económica y social que apuesta por el periodismo "reposado". Se compone por siete secciones ("Investigación", "Reportajes", "Noticias", "Entrevistas", "Perfiles", "Datos" y "Opinión”).

Tabla 10. Ficha de análisis de Crític

\begin{tabular}{|l|l|}
\hline \multicolumn{2}{|c|}{ Identidad del cibermedio } \\
\hline Año de creación & 2014 \\
\hline Fundadores & Sergi Picazo, Roger Palà, Joan Vila \\
\hline Director & Sergi Picazo, Roger Palà, Joan Vila \\
\hline Temática & Periodismo de investigación \\
\hline Secciones & $\begin{array}{l}\text { Investigación } \\
\text { Reportajes } \\
\text { Noticias } \\
\text { Entrevistas } \\
\text { Perfiles } \\
\text { Datos } \\
\text { Opinión }\end{array}$ \\
\hline Tipo de contenido & Especializado en investigación \\
\hline Formato & Digital + revista monográfica \\
\hline Propuesta de valor & Periodismo de investigación \\
\hline Tipo de sociedad & Modelo de ingresos \\
\hline Tipo de modelo de negocio & Cooperativa \\
\hline Fuentes de ingresos & $\begin{array}{l}\text { Freemium } \\
\text { monogrunding, suscripciones, publicidad, revista }\end{array}$ \\
\hline
\end{tabular}

Fuente: Elaboración propia (2019).

Su propuesta de valor se centra en apostar por el periodismo de investigación para combatir los "silencios mediáticos", priorizando el periodismo de datos y el fact checking. Además del sitio web, el cibermedio también edita anualmente una revista monográfica en papel llamada Dossier CRÍTIC. Los contenidos del proyecto son gratuitos, aunque algunos de ellos se publican inicialmente en cerrado durante uno o dos días para que los suscriptores puedan acceder de forma exclusiva. Es el caso del reportaje de investigación que el medio publica una vez por semana. Transcurrido este período, la información está en abierto al alcance de todos. El precio por suscripción oscila entre los 4,5 euros y los 5,3 euros al mes. Sin embargo, el medio ofrece la posibilidad de ampliar la cuota hasta 
12,5 euros mensuales. Los suscriptores obtienen ventajas como la consulta en primicia de todos los reportajes y entrevistas, descuentos y promociones, descarga del contenido o boletín informativo, entre otros. El medio nació a partir de una campaña de micromecenazgo a través de la plataforma Verkami, con la que obtuvo más de 45.000 euros. Además, también contó con la aportación económica (de entre 1.000 y 5.000 euros) de sesenta socios. Sus principales vías de financiación son la publicidad, los contenidos patrocinados (40\%) y los suscriptores (40\%). Otro $10 \%$ proviene de subvenciones o proyectos financiados por la Generalitat de Cataluña o por ayuntamientos. Su principal reto es conseguir más suscriptores para finalmente depender solamente de ellos como fuente de ingreso.

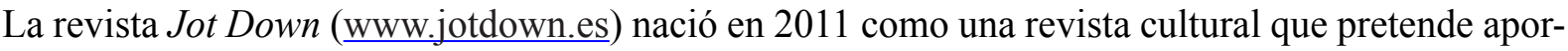
tar su punto de vista y perspectiva a través del humor, analizando la actualidad y "entretener sin ser superficiales e informar sin caer en una frialdad impersonal" (Jot Down, 2019). A partir de una sociedad civil, impulsan una revista digital especializada en cultura que apuesta por abordar los temas culturales y de ocio desde una perspectiva diferente y escribir sobre temas atemporales en profundidad. Se divide en nueve secciones ("Arte y letras", "Ciencia", "Cine y televisión", "Deportes", "Entrevistas", "Música", "Ocio y vicio", "Política" y "Sociedad"), que a su vez se dividen en más apartados. Junto a la extensión de los textos, la otra particularidad del medio es la estética, pues su apuesta gráfica es por el blanco y negro (ver tabla 11).

Tabla 11. Ficha de análisis de Jot Down

\begin{tabular}{|c|c|}
\hline \multicolumn{2}{|r|}{ Identidad del cibermedio } \\
\hline Año de creación & 2011 \\
\hline Fundadores & Ángel Luis Fernández y Ricardo J. González \\
\hline Director & Ángel Luis Fernández \\
\hline Formato & Magazine digital cultural + revista trimestral en papel \\
\hline Temática & Entrevistas y artículos extensos culturales \\
\hline Secciones & $\begin{array}{l}\text { Arte y letras } \\
\text { Ciencia } \\
\text { Cine y televisión } \\
\text { Deportes } \\
\text { Entrevistas } \\
\text { Música } \\
\text { Ocio y vicio } \\
\text { Política } \\
\text { Sociedad }\end{array}$ \\
\hline Tipo de contenido & Periodismo narrativo y atemporal \\
\hline Propuesta de valor & $\begin{array}{l}\text { Abordar la cultura y el ocio desde una perspectiva diferente y escribir sobre } \\
\text { temas atemporales, culturales y de manera extensa y en profundidad }\end{array}$ \\
\hline \multicolumn{2}{|r|}{ Modelo de ingresos } \\
\hline Tipo de sociedad & Sociedad Civil \\
\hline Tipo de modelo de negocio & $\begin{array}{l}\text { Contenido de acceso gratuito con posibilidad de suscribirse y obtener } \\
\text { algunas ventajas }\end{array}$ \\
\hline Fuentes de ingresos & $\begin{array}{l}\text { Fondos propios, publicidad, suscriptores, venta de revistas impresas, } \\
\text { distribución de cabeceras a terceros. }\end{array}$ \\
\hline
\end{tabular}

Fuente: Elaboración propia (2019).

Además de su versión en línea, el cibermedio cuenta con una cabecera en papel que se distribuye de forma trimestral. Desde 2015 y hasta febrero de 2019, el periódico El País publicaba mensualmente una versión reducida de esta revista, con el nombre de Jot Down Smart. El contenido de la plataforma online es gratuito, aunque el medio ofrece al usuario la posibilidad de suscribirse y obtener algunas ventajas como navegar sin publicidad, la suscripción de un año a la plataforma Filmin o recibir cuatro números de la revista impresa, entre otros, pagando una cuota mensual de entre 2,5 
euros y 8,3 euros. Para poner en marcha el proyecto los socios fundadores aportaron un capital de 30.000 euros. A pesar de ser un medio nativo digital, su principal fuente de ingresos es la venta de la revista impresa y otros productos editoriales, que suponen un $70 \%$ de los ingresos totales. E1 30\% restante proviene de la publicidad. Además, también organizan eventos y tienen una alianza con la empresa Filmin. Su principal reto es maximizar los ingresos por publicidad.

El proyecto FronteraD (www.fronterad.com) es una revista digital que habla sobre temas culturales, económicos y políticos, entre otros. Su equipo está formado por un director de arte, un director editorial y un webmaster. Su principal hito es hacer buen periodismo siguiendo la escuela anglosajona con un periodismo riguroso, imaginativo y original, estimulando el espíritu crítico de los lectores. La revista forma parte de una sociedad limitada y nació en 2009. Inicialmente, el proyecto estaba concebido para ser una revista en papel, pero por falta de fondos se decidió que sería en soporte digital. Su gran referente era The New Yorker por su formato pausado y con reporteros dedicados a investigar las historias por mucho tiempo (ver tabla 12).

Tabla 12. Ficha de análisis de FronteraD

\begin{tabular}{|l|l|}
\hline Año de creación & \multicolumn{1}{c|}{ Identidad del cibermedio } \\
\hline Fundadores & Alfonso Armada y Antonio Lafuente \\
\hline Director & Alfonso Armada \\
\hline Formato & Revista digital \\
\hline Temática & $\begin{array}{l}\text { Temas culturales, económicos, políticos y lugares olvidados por los grandes } \\
\text { medios }\end{array}$ \\
\hline Secciones & $\begin{array}{l}\text { Brújula (temas de carácter internacional) } \\
\text { Mientras tanto (blogs) } \\
\text { Acordeón (reportaje, ensayo y podcasts) } \\
\text { Arpa (autorretratos, perfiles, portafolio y cómic) } \\
\text { Universo elegante (ciencia y tecnología) } \\
\text { Sociedad del espectáculo (arte, letras, escenarios y pantallas) }\end{array}$ \\
\hline Tipo de contenido & Periodismo narrativo, riguroso, original, crónica y ensayo \\
\hline Propuesta de valor & Apuesta por los temas olvidados por los medios generalistas \\
\hline Tipo de sociedad & Sociedad limitada \\
\hline Tipo de modelo de negocio & Contenido gratuito \\
\hline Fuentes de ingresos & Aportaciones iniciales de familiares y amigos, publicidad, editorial FronteraD \\
\hline
\end{tabular}

Fuente: Elaboración propia (2019).

Se trata de una revista digital centrada en el periodismo narrativo, la crónica y el ensayo. El sitio web contiene seis secciones ("Brújula", "Mientras tanto", "Acordeón", "Arpa", "Universo elegante" y "Sociedad del espectáculo"). El nombre poco común de las secciones se debe a que el cibermedio entiende que el mundo no puede acotarse a las divisiones convencionales como internacional, nacional, local, economía o cultura. Su propuesta de valor es el trabajo sobre los temas olvidados por los medios generalistas. El contenido es gratuito en su totalidad y no hay posibilidad de suscripción, aunque el usuario puede registrarse para obtener un boletín semanal. El principal reto de FronteraD ha sido establecer un modelo de ingresos eficaz. Inicialmente hicieron una subasta de arte con la que recibieron unos 30.000 euros y alquilaron un espacio físico, compraron ordenadores y pagaron sueldos, aspectos que el propio fundador considera como errores. A partir de entonces, mantuvieron el medio con aportaciones de amigos y familiares. Más adelante se creó la editorial FronteraD, que actualmente es una fuente de ingresos de la plataforma. Además, una pequeña parte de los ingresos provienen de la publicidad, junto a la organización de actividades externas. Actualmente, indagan en otras vías de financiación, como aplicaciones para tabletas y móviles. 
Junto a los estudios de caso y las entrevistas, los dos grupos focales realizados destacan por aportar las siguientes conclusiones. Por un lado, todos los participantes coincidieron en que falta profundización en las noticias en Internet. Los internautas criticaron que, en el escenario informativo digital que brinda la Red, la información que el usuario encuentra en los distintos medios es muy parecida y no aporta ningún valor añadido. En esta línea, los participantes destacaron que, desde su punto de vista, prima la cantidad por encima de la calidad. Apuntan que existe una falta de profundización en las noticias y demandan una mayor y más completa cobertura y seguimiento de los hechos que permita comprender el origen de las temáticas abordadas. Además, destacan que los medios se guían por los gustos e intereses de la audiencia y dejan de hacer seguimiento a temas de interés e impacto. En este sentido, los usuarios señalan que prefieren pagar por un medio siempre y cuando éste ofrezca un valor añadido y no proporcione noticias de agencia o el mismo contenido que pueden encontrar en los medios generalistas. Más allá de la especialización del medio, valoran una mayor profundización en la información. En cuanto al modelo de negocio ideal, en los dos grupos focales desarrollados, los participantes apostaron por un modelo freemium como el idóneo.

\section{Discusión y conclusiones}

A partir del estudio de casos de los ocho cibermedios, la investigación ha podido analizar las principales características de su propuesta de valor y de modelo de ingresos, las motivaciones de su creación, así como los retos y las dificultades que encontraron y encuentran en la actualidad. En este sentido, a modo de discusión, el estudio permite señalar que este conjunto de cibermedios comparten su aparición en el territorio español durante el periodo la crisis económica, que también afectó a los medios de comunicación generalistas. En conjunto, los ocho casos seleccionados denotan un desencanto de sus creadores con el panorama mediático del momento y coinciden en subrayar la necesidad de idear proyectos ciberperiodísticos que trabajen desde un enfoque slow que priorice el contexto y el análisis en profundidad. A ello se une una conceptualización que propone una distribución en secciones alejada de las propuestas convencionales. Respecto a los modelos de ingresos, existen diferentes propuestas, pero todas ellas apuestan por una diversificación de sus fuentes de ingresos e identifican la rentabilidad como un reto permanente de sus respectivos proyectos.

Junto a los estudios de caso, el conjunto de entrevistas realizadas en el marco de la investigación, desembocan en las siguientes conclusiones. Por un lado, se observa una clara tendencia hacia la especialización. Uno de los aspectos comunes en la mayoría de los medios es que apuestan por diferenciarse y proporcionar información de calidad centradas en ámbitos temáticos o nichos muy acotados. Este aspecto valida la segunda hipótesis de la investigación. Por otro, los entrevistados coinciden en valorar la calidad por encima de la cantidad de contenidos informativos. En este sentido, los fundadores y responsables de los proyectos, se muestran contrarios a incluir en sus espacios noticias de agencia, priorizando el trabajo periodístico, la investigación y las piezas de calidad elaboradas con tiempo. Este aspecto está vinculado a una clara apuesta por la profundidad en detrimento de la inmediatez. Además, justifica el mayor protagonismo, en el conjunto de sus agendas, de temáticas atemporales, en las que se prioriza el trabajo de contextualización y la apuesta narrativa pulcra y refinada.

De este modo, a partir de los estudios de casos y de las entrevistas, el trabajo concluye, entre otros aspectos, que existe una tendencia generalizada hacia los medios que apuesta por los microtemas o nichos temáticos derivados de un enfoque especializado. Los entrevistados coinciden en señalar que los medios especializados van a absorber progresivamente un mayor protagonismo; mientras que los generalistas deberán reinventarse en el futuro. A lo anterior se une que el conjunto de directivos entrevistados reconoce que, en el lanzamiento de sus respectivos proyectos ciberperiodísticos, les afectó negativamente la falta de conocimientos a nivel empresarial. En esta línea, el principal reto 
con el que se encontraron los fundadores fue la carencia de competencias y habilidades sobre cómo crear sus respectivas empresas, afrontar cuestiones legales $u$ otros aspectos de naturaleza técnica.

De forma generalizada, el hito compartido por el conjunto de cibermedios analizados reside en la definición de estrategias para obtener mayores ingresos y, en muchos casos, suscriptores. Las suscripciones se presentan como la principal fuente de ingresos en las iniciativas ciberperiodístcas. Este aspecto está vinculado al hecho que la mayoría de los fundadores descarta la publicidad como modelo de ingreso de futuro y apuesta por las suscripciones. No obstante, los entrevistados reconoce que la publicidad va a seguir existiendo y que para algunos medios concretos continuará siendo un pilar importante de su financiación. A pesar de ello, los responsables inciden en la necesidad de diversificar las fuentes de financiamiento. Estos profesionales reconocen que no es viable disponer únicamente de una vía de ingresos. Además, curiosamente muchos de ellos a pesar de ser nativos digitales, presenta una línea de acción en papel o incluso dispone de una editorial como una de las vías principales de ingresos.

La investigación permite además corroborar que, como tendencia de cariz global, no existe en España una predisposición a pagar por los contenidos informativos del ciberespacio. Con relación a ellos, los expertos aseguran que es muy difícil sobrevivir solamente con los suscriptores, pues entre los internautas españoles no hay una tradición de pago por contenidos, a diferencia de Estados Unidos y el Reino Unido, e inciden en la necesidad de concienciar a la sociedad en este ámbito. Finalmente, la investigación permite concluir que el crowdfunding es una de las vías más utilizadas en la financiación de este tipo de cibermedios, especialmente, en sus etapas iniciales. El contenido del conjunto de los proyectos analizados suele aparecer en abierto. En este sentido, aunque algunos medios lanzan el contenido en cerrado durante un periodo de tiempo, al final lo abren. Ninguno de ellos presenta un modelo de negocio íntegramente premium, sino que optan por el modelo freemium o por propuestas directamente abiertas.

Partiendo de lo anterior, la investigación permite validar las dos hipótesis planteadas. Por una parte, respecto al primer supuesto ("Los medios nativos digitales han apostado por modelos de negocio centrados en la horizontalidad, la participación y el compromiso de su público"), la investigación concluye que los medios nativos digitales alternativos no pueden limitar su modelo de ingresos a la publicidad para ser sostenibles, por lo que efectivamente buscan otras vías de financiación como los suscriptores, alianzas con otras empresas, donaciones, ventas por el soporte impreso e incluso algunos crean una editorial paralela que les proporciona beneficios. Existe una importante apuesta por la participación económica de los suscriptores a pesar de la inexistencia en España de tradición de pago por contenidos. El estudio, no obstante, identifica muchas dudas acerca del futuro de los medios digitales y de un posible modelo de ingresos que funcione sin tener que depender del soporte impreso o de la publicidad. Por otra parte, respecto a la segunda hipótesis ("Los medios nativos digitales respaldan su modelo de negocio en una oferta temática que incide en contenidos centrados en la diversidad y en la especialización"), la investigación ha permitido verificar que el conjunto de los medios nativos digitales analizados se caracteriza por la búsqueda de un nicho de mercado muy especializado temáticamente frente a la oferta generalista de los medios más tradicionales. Existe, por tanto, una apuesta clara por la hipertematización.

La investigación deja por explorar diversos aspectos vinculados con los modelos de negocio, como el estudio relativo a la desaparición de algunos cibermedios, sus causas, o la evolución de la tipología de contenidos ofrecidos. A lo anterior se une la importancia de analizar de forma detallada el rol protagónico asumido por las redes sociales y otras plataformas dialógicas de internet en la sostenibilidad de este tipo de proyectos periodísticos concebidos desde y para el ciberespacio. Finalmente, resultaría de gran valor poder trasladar este tipo de investigación sobre los modelos de ingresos en los medios nativos digitales de carácter alternativos al ámbito internacional y, de este modo, poder desarrollar análisis comparativos en diferentes territorios o regiones a partir de sus propuestas y particularidades. 


\section{Bibliografía}

Adira, A., Carmona, N., et al (2018). Estándares e indicadores para la calidad informativa en los medios digitales. S.1.: Ediciones Egregius.

Albalad, J. M. (2018). Periodismo Slow. Fragua.

Burns, A. (2010). Oblique Strategies for Ambient Journalism. M/C Journal, 13(2), 1-5.

Bruns, A. (2012). Journalists and Twitter: How Australian News Organisations Adapt to a New Medium. Media International Australia Incorporating Culture and Policy, 144, 97-107.

Cabrera, M. Á. (coord.). (2010). Evolución tecnológica y cibermedios. Comunicación Social.

Casero-Ripollés, A. (2012). Contenidos periodísticos y nuevos modelos de negocio: evaluación de servicios digitales. El profesional de la información, 21(4), 341-346.

Carvajal, M., Valero Pastor, J. M. (2018). Fuentes de ingresos en la industria periodística española según sus responsables. Hipertext.net, 17, 83-94.

Cea Esteruelas, N. (2013). Estudio paneuropeo sobre el modelo de negocio y las fuentes de financiación de la radio pública en internet. Trípodos, 33, 33-52.

Cea Esteruelas, M. (2009). Modelo de negocio de la empresa periodística en Internet: El caso de Prisa. Revista Latina de Comunicación Social, 64, 938-950.

Chadwick, A. (2013). The hybrid media system: Politics and power. Oxford University Press.

Chan-Olmsted, S. \& Shay, R. (2016). The New Digital Media Value Network: Proposing an Interactive Model of Digital Media Value Activities. Icono 14, 14 (2), 46-74. https://doi.org/ 10.7195/ri14. v14i1.986

Demil, B., y Lecocq, X. (2009). Evolución de modelos de negocio: Hacia una visión de la estrategia en términos de coherencia dinámica. Universia Business Review, (23), 86-107.

Diezhandino, P. (coord.). (2008). Periodismo en la era de internet. Ariel.

Domínguez, E. y Pérez, J. (2012). Microperiodismos. Aventuras digitales en tiempos de crisis. UOC.

Domínguez, E. y Pérez, J. (2013). Microperiodismos II. Aventuras periodísticas digitales en tiempos de crisis. UOC.

Edo, C. (2002). Del papel a la pantalla. La prensa en internet. Comunicación Social Ediciones y Publicaciones.

Flores, J. y Aguado, G. (2005). Modelos de negocio en el ciberperiodismo. Fragua.

Gago, M., Toural, C., Limia, M., López, X. (2013). Modelos de negocio orientados al consumidor en los cibermedios españoles. En F. Sabés y J. Verón, (Coord.), Comunicación y la red: Nuevas formas de periodismo. Asociación de Periodistas de Aragón.

García, J. y González, J. (2012). Cibermedios nativos españoles: explorando modelos de rentabilidad. Trípodos, 30, 153-167.

Goyanes, M. (2015). Apoyo estructural en la intención emprendedora de estudiantes de periodismo y comunicación audiovisual en España. El profesional de la información, 24(1), 55-61. 
Haak, B., Parks, M. \& Castells, M. (2012). The Future of Journalism: Networked Journalism. International Journal of Communication, 1(6), 2923-2938.

Folker, H. \& Bruns, A. (2017). Journalistic Branding on Twitter: A Representative Study of Australian Journalists' Profile Descriptions. Digital Journalism, 5(1), 26-43.

García-Avilés, J. A. y González-Esteban, J. L. (2012). Cibermedios nativos españoles: explorando modelos de rentabilidad. Tripodos, 30, 153-167.

Hedman, U. \& Djerf-Pierre, M. (2013). The Social Journalist: Embracing the Social Media Life or Creating a New Digital Divide? Digital Journalism, 1(3), 368-385. https://doi.org/10.1080/21670 811.2013.776804

Jarvis, J. (2015). El fin de los medios de comunicación de masas. Gestión 2000.

Kwak, H., Changhyun L., Hosung P. \& Sue M. (2010). What is Twitter, a Social Network or a News Media? Paper presented at the Proceedings of the 19th International Conference on World Wide Web. Raleigh, 26-30.

López, X. y Pereira, X. (coords.). (2010). Convergencia digital. Reconfiguración de los medios de comunicación en España. Universidad de Santiago.

López-García, G. (ed.). (2005). El ecosistema digital: Modelos de comunicación, nuevos medios y público en internet. Universidad de Valencia.

Newman, N., Fletcher, R., Kalogeropoulos, A., Levy, D. \& Nielsen, R. (2019). Digital News Report 2019. Reuters Institute.

Newman, N., Fletcher, R., Kalogeropoulos, A., Levy, D. \& Nielsen, R. (2018). Digital News Report 2018. Reuters Institute.

Newman, N., Fletcher, R., Kalogeropoulos, A., Levy, D. \& Nielsen, R. (2017). Digital News Report 2017. Reuters Institute.

Neuberger, C., Nuernbergk, C. \& Langenohl, S. (2019). Journalism as Multichannel Communication. Journalism Studies, 20(9), 1260-1280.

Nuernbergk, C. (2016). Political Journalists' Interaction Networks: The German Federal Press Conference on Twitter. Journalism Practice, 10(7), 868-879.

Osterwalder, A., \& Pigneur, Y. (2016). Generación de modelos de negocio. Editorial Deusto.

Osterwalder, A. (2010). Generación de modelos de negocio. Editorial Deusto.

Palacio, L. (2018). Modelos de negocio de los medios digitales. Cuadernos de periodistas.

Pavlik, J. (2005). El periodismo y los nuevos medios de comunicación. Paidós.

Primack, B.A., Shensa, A., Sidani, J. E., Whaite, E. O., Lin, L.Y., Rosen, D., Colditz, J. B., Radovic, A. \& Miller, E. (2017). Social Media Use and Perceived Social Isolation Among Young Adults in the U.S. American Journal of Preventive Medicine, 53(1), 1-8. https://doi.org/10.1016/j. amepre.2017.01.010

Rheingold, H. (2002). Masas inteligentes. Gedisa.

Rodríguez, A. y Soloaga, C. (2017). Calidad vs cantidad. El combate del siglo en contenidos. S.1.: Semrush. 
Rosique Cedeillo, G. y Barranquero-Carretero, A. (2015). Periodismo lento (Slow journalism) en la era de la inmediatez. Experiencias en Iberoamérica. El profesional de la información, 24(4), 451-462.

Rubio Hancock, J. (3 de febrero de 2019). La nueva prensa digital se enfrenta a su primera gran crisis. El País - Verne. https://verne.elpais.com/verne/2019/02/01/articulo/1549038378_127709. html

Salaverría, R., Martínez-Costa Pérez, M. P. y Breiner, J. (2018). Mapa de los cibermedios de España en 2018: análisis cuantitativo. Revista Latina de Comunicación Social, 73, 1034-1053.

Salaverría, R. (2008). Ciberperiodismo: diez años de prensa digital en España. En J. J. FernándezSanz(ed.), Prensa especializada actual. Doce calas. McGraw-Hill.

Sembramedia (2018). Punto de inflexión. Impacto, amenazas y sustentabilidad: estudio de emprendedores de medios digitales latinoamericanos. OmidyarNetwork - Sembramedia. http:// data.sembramedia.org/wp-content/uploads/2017/09/Punto-de-Inflexion-SembraMedia-span-7-24. pdf

Tejedor, S., Carniel-Bugs, R. y Giraldo-Luque, S. (2018). Los estudiantes de Comunicación en las redes sociales: estudio comparativo entre Brasil, Colombia y España. Transinformação, 30(2), 267-276. https://doi.org/10.1590/2318-08892018000200010

Tejedor, S. y Cervi, L. (2017). Análisis de los estudios de Periodismo y Comunicación en las principales universidades del mundo. Competencias, objetivos y asignaturas. Revista Latina de Comunicación Social, 72, 1.626-1.647.

Tejedor, S. (2007). Periodismo «mashup». Combinación de recursos de la web social con una finalidad ciberperiodística. Anàlisi, 35, 17-26.

Vara, A. (2011). Modelo de negocio y publicidad en medios on-line. Material docente de la UOC. UOC.

Vara, A., Díaz-Espina, C. (2012). Modelos de negocio y estrategia editorial: el caso del wsj.com. Revista de comunicación, 11, 110-12. 